\title{
Breeding behavior and reproductive success of Grey-headed Lapwing Vanellus cinereus on farmland in central Japan
}

\author{
Masao TAKAHASHI ${ }^{\# * *}$ and Kyohsuke OHKAWARA \\ Ecological Laboratory, Division of Biological Science, Graduate School of Natural Science and Technology, Kanazawa Univer- \\ sity, Kanazawa 920-1192, Japan.
}

\section{ORNITHOLOGICAL SCIENCE \\ (C) The Ornithological Society of Japan 2007}

\begin{abstract}
Certain lapwing species (Vanellus spp.) breed in agricultural habitats, where they are dependent on particular features of such artificial conditions. The breeding behavior and breeding success of the Grey-headed Lapwing Vanellus cinereus were examined on farmland in central Japan. Thirty-five pairs in 2004 and 42 pairs in 2005 were observed nesting on farmland consisting mainly of rice fields. Nests appeared to be distributed such that aggregations seemed to function as semicolonies. Farming practices seriously affected breeding success: 33 (42.9\%) breeding attempts were prevented during farming cultivation and flooding in spring. In 2004, only $16(45.7 \%)$ pairs produced fledglings, and in 2005 only $14(33.3 \%)$ pairs were successful. Territory size was also a factor affecting breeding success; territory area was positively correlated with the number of fledglings produced per nest. Greyheaded Lapwing parents intensively defended their nests and chicks; furthermore, group defense by multiple adults was also observed frequently. Defensive behavior was mainly directed against avian predators such as crows (Corvus spp.) and raptors, with group defense more frequently against raptors. Group defense was also more likely to occur where nests were close together, and it seemed that such defense was effective in increasing the number of chicks hatched. The breeding success of Greyheaded Lapwing was found to be influenced both by environmental and behavioral factors.
\end{abstract}

Key words Breeding, Defensive behavior, Farmland, Grey-headed Lapwing, Territory, Vanellus cinereus
The genus Vanellus is comprised of 22 species of large plovers or lapwings (Perrins \& Middleton 1984), several of which commonly breed in agricultural areas (Sonobe \& Usui 1993). The breeding behavior of such species has become adapted to manmade environments, with breeding success influenced by the particular features of farmland habitats (Galbraith et al. 1984; Henderson et al. 2002; Sheldon et al. 2004). For example, in the Northern Lapwing Vanellus vanellus, which mainly breeds in open areas such as grassland, pasture and wheat field (Galbraith et al. 1984; Sheldon et al. 2004), clutches are frequently destroyed during harrowing and spring cultivation (Galbraith 1988; Shrubb 1990). Such serious

\footnotetext{
(Received 23 June 2006; Accepted 19 February 2007)

\# Corresponding author, E-mail: hachi77vanellus@yahoo.co.jp

* Present address: Laboratory of Animal Ecology, Department of Life Sciences, Faculty of Science, Rikkyo University, Tokyo 171-8501, Japan
}

damage has a heavy impact on the breeding success of the Northern Lapwing. Furthermore, both the density and species richness of nest predators are higher in farmland habitats (Andrén 1992; Marini et al. 1995). In pastures in northeastern England, for example, $75.6 \%$ of Northern Lapwing clutches were taken by an avian predator, the Carrion Crow Corvus corone (Baines 1990). The breeding success of lapwings living in farmlands is strongly dependent on the features of the habitat.

Behavioral factors also affect the breeding success of lapwings. Anti-predator strategies are well known among members of the genus Vanellus (Elliot 1985a, b; Walters 1990; Ohno 1996; Kis et al. 2000). Antipredator behavior has been reported as contributing to breeding success in many bird species, for example in the Greater Golden-Plover Pluvialis apricaria, the Eurasian Dotterel Eudromias morinellus (Byrkjedal 1987), and the Fieldfare Turdus pilaris (Wiklund \& 
Andersson 1994). Many lapwing species, such as the Long-toed Lapwing V. crassirostris and the Blacksmith Plover $V$. armatus, respond aggressively to predators entering their territory and approaching their nest, and use various defensive behaviors such as alarm calling, mobbing, and striking (Walters 1990). The nest survival and hatching success of Northern Lapwings frequently depends on defense (Berg et al. 1992), and Elliot (1985b) demonstrated (using artificial nest experiments) that in the Northern Lapwing nest defense behavior was effective at excluding avian predators and at reducing the risk of nest predation.

In Japan, there is only one breeding Vanellus species (Sonobe \& Robinson 1985; Brazil 1991). The Grey-headed Lapwing Vanellus cinereus breeds in agricultural areas, particularly in fields for rice production (Okugawa et al. 1970). Rice fields comprise about half the farmland area of Japan (MAFF 1998), and such fields, which are flooded for part of the growing season, have been recognized as important habitats for waterbirds in Europe, North America, and Japan (Lane \& Fujioka 1998; Maeda 1998, 2001; Fujioka \& Yoshida 2001; Elphick \& Oring 2003). Given their association with such habitats, it seems likely that the Grey-headed Lapwing has various and specific adaptations to the features of rice fields. In this study, we observed the breeding behavior of the Grey-headed Lapwing on farmland in central Japan and investigated the factors affecting breeding success, in particular: farming practice, nest predation, and anti-predator behavior. The aim of this research was to further elucidate the evolutionary advantages of adaptation to agricultural habitats among Vanellus species.

\section{METHODS}

\section{1) Study site}

In 2004 and 2005, field observations were conducted from April to July, in a 280.9 ha area of farmland in Kaga city, Ishikawa prefecture, central Japan $\left(36^{\circ} 18^{\prime} \mathrm{N}, 136^{\circ} 17^{\prime} \mathrm{E}\right.$; see Fig. 1). The study site consisted of rice fields $(89.7 \%)$, bean fields $(8.2 \%)$ and fallow land $(2.1 \%)$. The rice fields are typically plowed then flooded for planting in late March before rice is planted in late April.

\section{2) Observation of nest distribution}

Based on preliminary observations of the study area, we established seven study plots $(A-G)$ where
Grey-headed Lapwings nested. All seven plots were in farmland (mainly rice fields), and had areas ranging from 24.7 ha to 72.5 ha. From early April until June, at intervals of 4-6 days, each area was explored slowly on foot from 06:00 to 18:00, and searched for lapwings and their nests. When they were located, their positions were recorded on a map (scale $1 / 10,000)$, and the habitat type surrounding each nest was recorded.

\section{3) Measurement of territory size}

During observations of each nest, the location of the adults was plotted on a map. When they moved more than $5 \mathrm{~m}$, new points were recorded. Such observations were made 3-15 times for each pair, and each observation period was of 1-3 hours. Observation was continued until the pairs abandoned their nests or finished breeding. The territory size of each pair was measured after mapping. In estimating territory size, Berg's (1993) method was used. All observation points for each pair were plotted on a map and the outermost points were connected to form a minimum convex polygon, allowing estimation of the size of each territory.

\section{4) Observation of breeding conditions}

Each pair and each nest was continuously checked from a distance, at intervals of 4-6 days from April to July, so as to determine breeding stage. When all eggs had been laid, they were counted to determine clutch size. A nest was regarded as having failed when the nest suddenly became empty; in particular, when a clutch was completely lost, this was regarded as nest predation. After hatching, the number of chicks was counted. Since the chicks were mobile on open land within the parent's territory, we were able to count the number of chicks and fledglings during normal long-range observations. In this paper, fledglings are defined as juveniles of adult size, while birds smaller than adult size are defined as chicks. When parents with fledglings moved away from their territory, they were regarded as having finished breeding.

\section{5) Observations of anti-predator behavior}

In order to examine the effect of anti-predator behavior on breeding, the care and defensive behaviors of parents were observed. The parents of 87 nests were observed directly for 1-3 hours, on 3-15 occasions. To avoid disturbing the pairs, we observed them from a car at a distance (usually $150 \mathrm{~m}$ ) with 

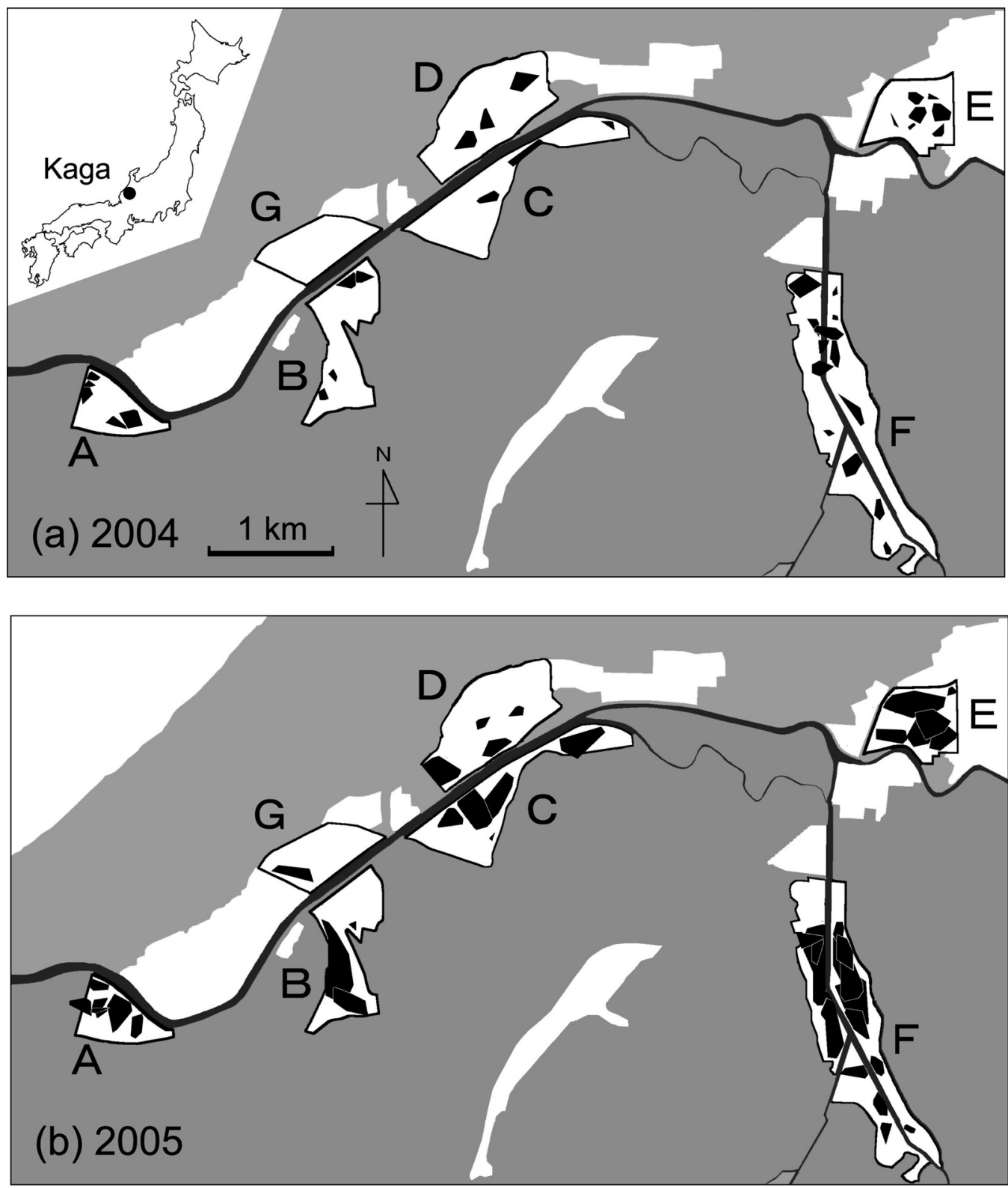

\section{:Territory range $\square$ :Study plot (A-G) $\square$ : Other habitats}

Fig. 1. Location of the study plots $(A-G)$ and territories of lapwing pairs. In (a) 2004 (35 pairs) and (b) 2005 (42 pairs).

binoculars and a telescope. The frequencies of: parental behavior, nest maintenance, incubation, and defense of the nest or chicks, were all recorded. When defense occurred, the following categories were also recorded: the species of predator or invader, the number of adults attacking, and the behavioral pattern of defensive behavior. Defensive behavior was classified in detail; six patterns were recorded: 1) alarm calling, 2) flying around the predator, 3) diving at the predator, 4) pecking attack, 5) crouched run and 6) injury-feigning (Walters 1990). Observations were conducted every 4-6 days from April to July. Simultaneously, the numbers of chicks and fledglings were also checked. Additionally we examined the effect of nest distribution on defensive behavior, particularly the nearest distance among 
Table 1. Survival of the Grey-headed Lapwing nests in various habitats in two years. Pairs with fledglings were regarded as having bred successfully. In rice fields, breeding success was lower, and most nests were lost as a result of farming practices, although lapwings nested there frequently.

\begin{tabular}{|c|c|c|c|c|c|}
\hline \multirow{2}{*}{\multicolumn{2}{|c|}{ Habitat }} & \multirow[b]{2}{*}{$\mathrm{N}$} & \multicolumn{2}{|c|}{ Failure (\%) } & \multirow[t]{2}{*}{ Successful (\%) } \\
\hline & & & By farming & By others & \\
\hline \multirow[t]{2}{*}{ Rise field } & cultivated field & 24 & $16(66.7)$ & $3(12.5)$ & $5(20.8)$ \\
\hline & levee & 28 & $10(35.7)$ & $9(32.1)$ & $9(32.1)$ \\
\hline Bean field & & 13 & 7 (53.9) & $1(7.7)$ & $5(38.5)$ \\
\hline Fallow & & 5 & 0 & 0 & $5(100)$ \\
\hline Unknown & & 7 & - & - & - \\
\hline
\end{tabular}

nests (Šálek \& Šmilauer 2002). The distance between nests was measured from field observation maps and nearest-neighbor inter-nest distances were estimated for all nests (2004: $N=35,2005: \mathrm{N}=52$ ). Mean nearest-neighbor inter-nest distances were calculated for each plot, and the relationship between this distance and the frequency of nest defense was analyzed.

6) Analysis of factors affecting breeding success

Field observations indicated that the breeding success of the Grey-headed Lapwing is dependent on both environmental and behavioral factors. Therefore we analyzed the most important factor by using a general linear mixed model. Data from all pairs nesting during the two-year study was used in the analysis. Breeding success was evaluated as the number of fledglings reared by each pair. As variables of breeding performance and behavioral factors, clutch size, chick number, territory size, nearest-neighbor internest distance and defense frequency (the number of defensive behaviors observed per hour in each area), were used. Territory sizes and inter-nest distances were transformed to log values. As environmental variables, the following parameters were recognized: nest destruction by farming practices (destroyed $=1$, not destroyed $=0$ ), nest predation (predation $=1$, no predation $=0$ ), nesting site microhabitats (cultivated rice field, levee, bean field, and fallow), study plot (A-G), and year (2004 and 2005). Microhabitats and study plot were used as category variables. Pair identity was used as a random effect in the model.

\section{RESULTS}

1) Nest distribution and breeding success

A total of 77 breeding pairs (2004: 35 pairs and 2005: 42 pairs) were recorded in the study area and the territories of each pair were mapped (see Fig. 1).
All pairs nested in farmland habitats. The nests tended to be extremely aggregated, though a few nests were isolated from the nest group. Nest grouping suggests that this species nests in a semi-colony. Fifty-two pairs $(67.5 \%)$ nested in rice fields, cultivated fields and on levees, or on wide farm paths between cultivated fields (Table 1). Eighteen (23.4\%) other pairs nested in bean fields and fallow fields. However, $46(59.7 \%)$ pairs failed to breed (18 in 2004; 28 in 2005): 33 (42.9\%) were destroyed by flooding or during cultivation with farming machines; and 13 pairs $(16.9 \%)$ failed for other reasons. Nest predation was not very frequent (4 nests; $5.2 \%$ ). Of the 28 failed nests in 2005 , only nine pairs $(32.1 \%)$ tried to produce a second clutch, although re-laying could not be accurately confirmed in 2004 because some pairs started to build their nests earlier in that year, and some nests had already failed before observations commenced. The frequency of successful breeding was higher in bean fields and fallow land than in rice fields in both years $(\mathrm{P}<0.01, \mathrm{G}=18.8$, Gtest, Table 1); however, the area of such habitats was smaller (less than 10.3\%) than for rice fields in the study area.

\section{2) Characteristics of nesting and breeding}

In the study site, 77 pairs nested over the two-year study period. In each area, 1-21 nests were observed and nest density was calculated to be 0.04-0.31 nest/ha. Territory size was $0.08-7.8$ ha (mean \pm SD: $1.7 \pm 1.7$ ha, $\mathrm{N}=74)$, and did not differ significantly among plots (2004: $\mathrm{P}=0.05,2005$ : $\mathrm{P}=0.69$; one-way ANOVA). The mean territory size in each study plot was not related to nest density (2004: $\mathrm{P}=0.83,2005$ : $\mathrm{P}=0.48$; linear correlation).

In 2004 and 2005, 33 pairs $(42.9 \%, \mathrm{~N}=77)$ bred successfully (see Table 2). The breeding success rate differed significantly among plots in both 2004 
Table 2. Characteristics of breeding by lapwings in seven study plots.

\begin{tabular}{|c|c|c|c|c|c|c|c|c|c|c|}
\hline \multirow[b]{2}{*}{ Plot } & \multicolumn{5}{|c|}{2004} & \multicolumn{5}{|c|}{2005} \\
\hline & Nests & $\begin{array}{l}\text { Clutch } \\
\text { size } \\
(\mathrm{N})\end{array}$ & $\begin{array}{c}\text { Mean } \pm \text { SD } \\
\text { number } \\
\text { of chicks }\end{array}$ & $\begin{array}{c}\text { Number } \\
\text { of } \\
\text { fledglings }\end{array}$ & $\begin{array}{c}\text { Breeding } \\
\text { success } \\
(\%)\end{array}$ & Nests & $\begin{array}{l}\text { Clutch } \\
\text { size } \\
(\mathrm{N})\end{array}$ & $\begin{array}{c}\text { Mean } \pm S D \\
\text { number } \\
\text { of chicks }\end{array}$ & $\begin{array}{c}\text { Number } \\
\text { of } \\
\text { fledglings }\end{array}$ & $\begin{array}{c}\text { Breeding } \\
\text { success } \\
(\%)\end{array}$ \\
\hline A & 5 & $3.8 \pm 0.5(4)$ & $1.8 \pm 1.8$ & $0.6 \pm 0.9$ & 40 & 8 & $3.4 \pm 0.9(5)$ & $0.5 \pm 1.4$ & 0 & 0 \\
\hline $\mathrm{B}$ & 4 & $3.7 \pm 0.6$ & $1.0 \pm 0.8$ & $0.5 \pm 0.6$ & 50 & 3 & $3.7 \pm 0.6$ & $2.0 \pm 2.0$ & $1.0 \pm 1.7$ & 33.3 \\
\hline $\mathrm{C}$ & 3 & $2.5(2)$ & $0.7 \pm 1.2$ & $0.7 \pm 1.2$ & 33.3 & 6 & $3.8 \pm 0.4(5)$ & $1.2 \pm 1.6$ & $0.7 \pm 0.8$ & 50 \\
\hline $\mathrm{D}$ & 3 & $4.5(2)$ & 0 & 0 & 0 & 4 & $4.0 \pm 0(4)$ & $0.8 \pm 1.5$ & $0.8 \pm 1.5$ & 25 \\
\hline $\mathrm{E}$ & 7 & $3.3 \pm 0.8(6)$ & $1.6 \pm 1.5$ & $0.9 \pm 1.2$ & 42.9 & 9 & $4.0 \pm 0(9)$ & $2.3 \pm 1.9$ & $1.0 \pm 1.3$ & 44.4 \\
\hline $\mathrm{F}$ & 13 & $3.8 \pm 0.5$ & $1.7 \pm 1.5$ & $1.2 \pm 1.1$ & 61.5 & 21 & $3.7 \pm 0.5(20)$ & $1.4 \pm 1.6$ & $0.8 \pm 1.2$ & 38.1 \\
\hline $\mathrm{G}$ & 0 & - & - & - & - & 1 & $4(1)$ & 4 & 0 & 0 \\
\hline Total & 35 & $3.6 \pm 0.9(21)$ & ) $1.4 \pm 1.4$ & $0.8 \pm 1.0$ & 45.7 & 52 & $3.8 \pm 0.5(47)$ & $1.4 \pm 1.7$ & $0.7 \pm 1.1$ & 32.7 \\
\hline
\end{tabular}

$\left(\mathrm{P}<0.01, \chi^{2}=57.4\right)$, and $2005\left(\mathrm{P}<0.01, \chi^{2}=89.8, \chi^{2}\right.$ test). The clutch size ranged from one to five eggs, although it was usually four eggs $(73.5 \%, \mathrm{~N}=68)$. The incubation period was 24-27 days. After hatching, the chicks were reared within the parental territory for 43-49 days. The parents also lived within and around their territory until the chicks matured. The mean number of hatched chicks per nest was $1.4 \pm 1.6$ individuals and the mean number of fledglings was $0.7 \pm 1.1(\mathrm{~N}=87)$, and did not differ among the plots (2004: chicks $\mathrm{P}=0.56$, fledglings $\mathrm{P}=0.68 ; 2005$ : chicks $\mathrm{P}=0.19, \quad$ fledglings $\mathrm{P}=0.63$, One-way ANOVA, Table 2).

For 20 pairs in 2004 and 25 pairs in 2005 that hatched chicks successfully, the influence of nest density and territory size on breeding success was examined by regression analysis. Nest density in the plot was not related to the mean number of chicks or fledglings (chicks $\mathrm{P}=0.31$, fledglings $\mathrm{P}=0.20$, linear correlation), whereas territory size was positively correlated with the number of fledglings (2004: $\chi^{2}=4.8, \mathrm{P}<0.05 ; 2005: \chi^{2}=6.6, \mathrm{P}<0.01$, logistic regression, Fig. 2), although it was not correlated with the number of chicks (2004: $\mathrm{P}=0.20 ; 2005$ : $\mathrm{P}=0.28)$.

3) Defensive behavior and its effect on breeding success

Defensive behavior was directly observed for 35 pairs in 2004 and 42 pairs in 2005. A total of 625 defensive incidents relating to nests and chicks was observed during the breeding season from April to July. When enemies (such as Carrion Crow) approached territories, nests or chicks, parents responded intensively. First they began calling sharply in alarm; then, they threatened the intruder by flying close to them as

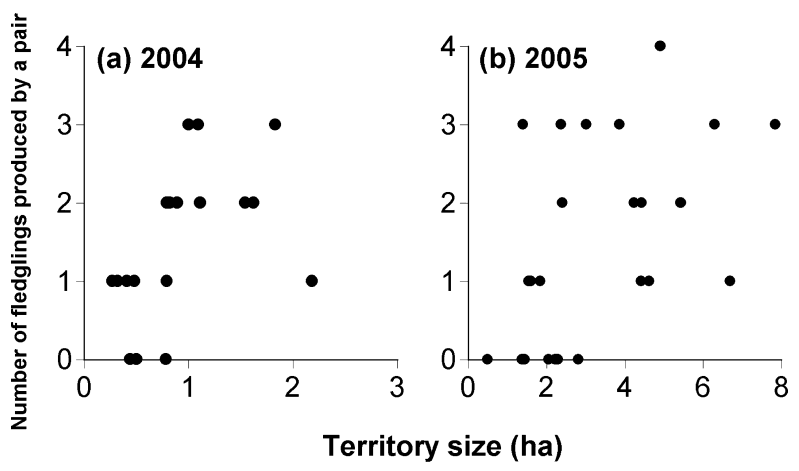

Fig. 2. Relationship between a pair's territory size and the number of fledglings produced. In (a) 2004 (16 successful pairs) and (b) 2005 (17 successful pairs).

in predator mobbing; finally, they dived and struck the intruder repeatedly. This response continued until the intruder left the area of the colony.

Of 625 defense incidents, the majority (368; $58.9 \%$ ) was performed by a single adult, a further $200(32.0 \%)$ were performed by two adults and 57 (9.1\%) were by more than three adults. The largest number of adults observed involved in a defensive incident was 16. Defensive behavior was directed at 30 kinds of intruders (see Fig. 3), 58.1\% of the defensive incidents were to avian predators. The commonest avian predators were Carrion Crow Corvus corone, Black Kite Milvus migrans, and Eastern Marsh Harrier Circus spilonotus. The frequency of group defense was highest when directed at a raptor $(\mathrm{P}<0.01$, $\chi^{2}=28.6, \chi^{2}$-test, Fig. 3).

Defensive pattern was also related to nest distribution, particularly the distance to the next nearest nest. The mean inter-nest distance was negatively correlated with the frequency of group defense by more 
(a)

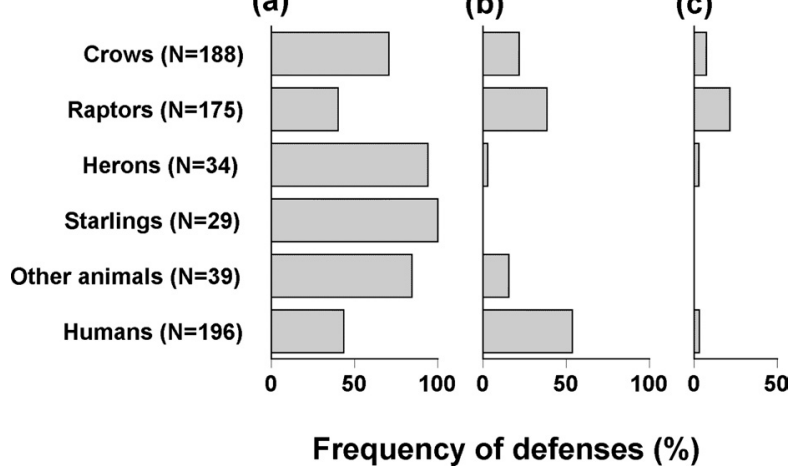

Fig. 3. Defensive behavior by lapwings against six types of predators and intruders. Three types of defense patterns: (a) single adults, (b) two adults, and (c) three or more adults.

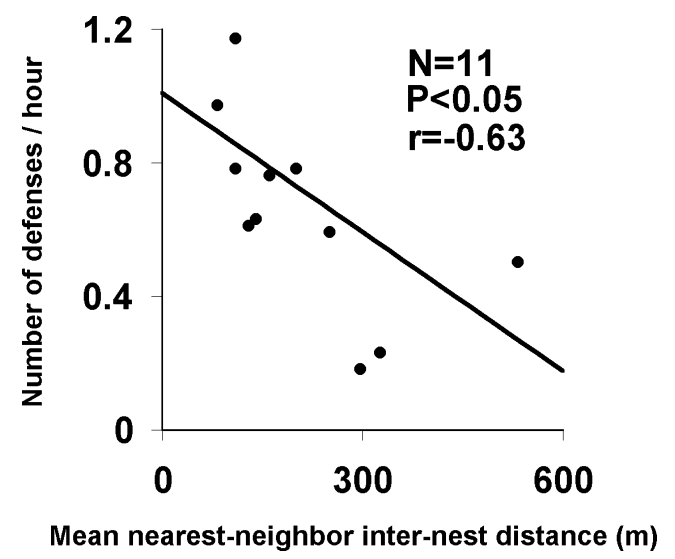

Fig. 4. Relationship between mean nearest inter-nest distance and the frequency of group defense. Defense by more than two adults was defined as group defense.

than two adults $(\mathrm{P}<0.05, \mathrm{r}=-0.63$, Fig. 4). This means that group defense occurred more frequently in areas where pairs nested close together. Furthermore, the mean number of chicks hatched by a pair increased with the frequency of defense (including defense by singles and groups), although the correlation was not significant (2004: $\mathrm{P}=0.07 ; 2005$ : $\mathrm{P}=0.13$, Fig. 5). Defense was probably effective in assuring incubation and hatching success.

4) Factors affecting breeding success

Data from 61 nests (2004 and 2005 combined) were available for the analysis of the factors affecting breeding success. The general linear mixed model accounted for $73.3 \%$ of the original deviance $\left(\mathrm{F}_{9,51}=6.6, \mathrm{P}<0.0001\right)$. Tests for the effects of each factor showed that breeding success is most closely related to the microhabitat of the nesting site (Table

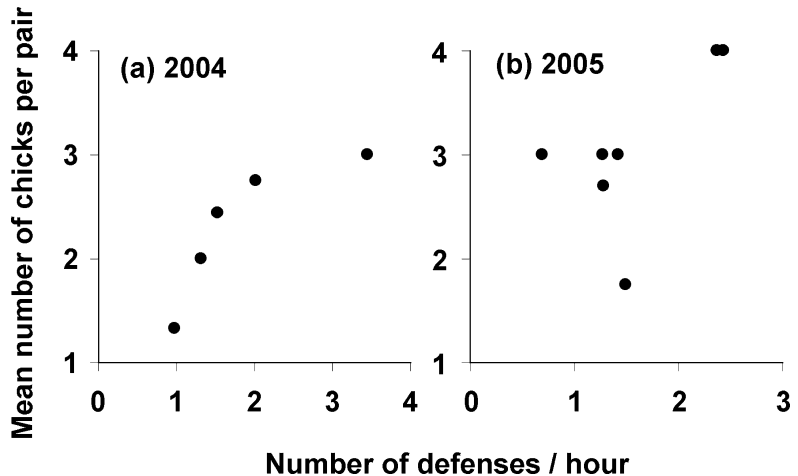

Fig. 5. Relationship between the frequency of defensive behavior and the mean number of chicks hatched per nest. In both 2004 (a) and 2005 (b), the number of chicks tended to be higher in plots where defense was more frequent, although the correlation was not significant (2004: $\mathrm{P}=0.05 ; 2005: \mathrm{P}=0.13)$.

Table 3. Results of a general linear mixed model testing for parameters affecting breeding success. The model includes the random effect of pair identity. Only the effect of microhabitat is significant.

\begin{tabular}{lrrrr}
\hline \multicolumn{1}{c}{ Factor } & $\begin{array}{c}\text { Parameter } \\
\text { estimate }\end{array}$ & SE & F & P \\
\hline Intercept & 0.46 & 0.84 & & \\
Clutch size & -0.05 & 0.19 & -0.29 & 0.77 \\
Chick number & 0.19 & 0.18 & 1.03 & 0.31 \\
Territory size & 0.04 & 0.11 & 0.34 & 0.74 \\
Nearest-neighbor & -0.04 & 0.13 & -0.27 & 0.79 \\
$\quad$ inter-nest distance & & & & \\
Defense & -0.09 & 0.2 & -0.45 & 0.66 \\
Microhabitat & 0.32 & 0.16 & 2.06 & 0.04 \\
$\quad$ of nesting & & & & \\
Farming practice & -0.75 & 0.56 & -1.33 & 0.19 \\
Nest predation & -1.09 & 0.86 & -1.27 & 0.21 \\
Study plot & 0.01 & 0.07 & 0.08 & 0.94 \\
Year & 0.22 & 0.36 & 0.62 & 0.54 \\
\hline
\end{tabular}

3). Although the effects of other variables were not significant, farming practices had a negative effect, with nests in rice fields being frequently destroyed as a result of farming practices. Probably, the effect of the microhabitat of the nesting site is dependent on nest destruction by farming practices.

\section{DISCUSSION}

The breeding success of the Grey-headed Lapwing was found to be influenced by both environmental and behavioral factors. Statistical analysis revealed that breeding success was dependent on the micro- 
habitat of the nesting site, and that breeding failure was commonly the result of disturbance during farming in rice fields. Given the high failure rate there, why does the Grey-headed Lapwing choose to nest in rice fields? Resource abundance appears to be one of the main factors driving their selection of this habitat. Farmland with various microhabitats gives rise to a high diversity of organisms as food for lapwings (Yamazaki et al. 2001, 2003). In particular, rice fields supply birds with various food resources including earthworms, aquatic arthropods, Diptera, Hemiptera and small ground-dwelling beetles. If the nest escapes disturbance from farming practices, foraging efficiency may be remarkably enhanced, resulting in high breeding success, and the benefit may be greater than from safe nesting in other less productive habitats.

The Northern Lapwing also prefers to nest in farmland habitats despite serious damage to nests from farming practices (Berg et al. 1992); however Northern Lapwings frequently $(66.1 \%)$ produce a second clutch if the first is lost, and hatching success of the second clutch was enhanced by environmental conditions in farmland habitats. Thus, the efficient reproductive output of the second clutch compensated for the loss of the first clutch. In Gray-headed Lapwings, nine of the failed pairs $(32.1 \%)$ in 2005 produced second clutches. Furthermore, in the year after the main study (2006), 38.2\% of failed pairs in this area were observed to produce a second clutch (Takahashi unpublished data). Although it is unclear whether the production of a second clutch compensates for the loss of the first clutch, the production of such a clutch is possibly beneficial for the Grey-headed Lapwing as it is for the Northern Lapwing.

In many territorial birds, breeding success is linked with territory qualities such as: position, location, predation risk, landscape structure, and food resources (e.g., Komdeur 1996; Côté 2000; Pärt 2001). It is well known that territory size is related to the abundance of food resources (Lack 1954, 1966). In the Grey-headed Lapwing, territory size affected the number of fledglings produced, although not the number of chicks. This suggests that a larger territory allows the parents to rear their fledglings more efficiently. The fledglings of ground-nesting waders are mobile after hatching and are able to forage by themselves. A larger territory provides the fledglings with a larger feeding area with various microhabitats and food resources. Thus the territory of the Grey-headed Lapwing functions as a nesting site for the adults and as a foraging area for the fledglings. Therefore, it is more advantageous for them to defend a larger territory.

In farmland habitats, predation risk is relatively high (Andrén 1992; Marini et al. 1995). In the Northern Lapwing, the frequency of predation is lower when birds nest on open land with little or no vegetation, because they are easily able to see predators approaching and thus are able to defend their nests more effectively (Galbraith 1988; Berg et al. 1992). The Grey-headed Lapwing also usually nests on open land in rice fields, cultivated areas or levees, and never nests in habitats where their nests would be hidden; furthermore, they exhibit intensive defensive behavior that contributes to facilitating breeding success (particularly affecting chick numbers), and defense was frequently performed by multiple members of a semi-colony. Such group defense by colony members has been reported in many bird species, for example in the Sandwich Tern Sterna sandvicensis (Veen 1977), Bank Swallow Riparia riparia (Hoogland \& Sherman 1976), and Fieldfare Turdus pilaris (Wiklund \& Andersson 1994). In general, group defense originates from colonial breeding, and therefore the pattern and frequency are strongly dependent on the aggregation or distribution pattern of nests within the colony (Elliot 1985a; Kis et al. 2000). In the Grey-headed Lapwing, group defense is likely to occur in plots where the pairs nest close together. A similar pattern was observed in a Northern Lapwing colony, perhaps because the defense range of each pair overlapped in a dense colony (Elliot 1985b). Moreover, the frequency of group defense was dependent on the type of intruder/predator and was frequently performed against avian predators especially raptors. These defense modes seem efficient at reducing nest predation. Thus the breeding success of the Grey-headed Lapwing was dependent on behavioral factors. It was also strongly affected by various environmental factors, microhabitat of farmland, territory size, and predation risk. The collection of more data combining both field observations and experiments will reveal more detail concerning the breeding behavior and factors effecting the breeding success of the Grey-headed Lapwing.

\section{ACKNOWLEDGMENTS}

We are grateful to H. Tajiri and N. Nakagawa, of the Wild Bird Society of Japan, for supporting our fieldwork, and Y. Yamamoto for his support of our farmland research. We also thank M. Nakagawa and H. Wakisaka for their help during our 
observations of lapwings. Cordial thanks to M. Brazil and anonymous referees for their comments and improvements to our manuscript.

\section{REFERENCES}

Andrén H (1992) Corvid density and nest predation in relation to forest fragmentation: a landscape perspective. Ecology 73: 794-804.

Baines D (1990) The roles of predation, food and agricultural practice in determining the breeding success of the lapwing (Vanellus vanellus) on upland grasslands. J Anim Ecol 59: 915-929.

Berg $\AA$ (1993) Habitat selection by monogamous and polygamous lapwings on farmland-the importance of foraging habitats and suitable nest sites. Ardea 81: 99-105.

Berg Å, Lindberg T \& Kallebrink KG (1992) Hatching success of lapwings on farmland: differences between habitats and colonies of different sizes. J Anim Ecol 61: 469-476.

Brazil MA (1991) The birds of Japan. Smithsonian Institution Press, Washington, DC.

Byrktedal I (1987) Antipredator behavior and breeding success in Greater Golden Plover and Eurasian Dotterel. Condor 89: 40-47.

Côté SD (2000) Aggressiveness in king penguins in relation to reproductive status and territory location. Anim Behav 59: 813-821.

Elliot RD (1985a) The effects of predation risk and group size on the anti-predator responses of nesting lapwings Vanellus vanellus. Behavior 92: 168-187.

Elliot RD (1985b) The exclusion of avian predators from aggregations of nesting lapwings (Vanellus vanellus). Anim Behav 33: 308-314.

Elphick CS \& Oring LW (2003) Conservation implications of flooding rice fields on winter waterbird communities. Agric Ecosyst Environ 94: 17-29.

Fujioka M \& Yoshida H (2001) The potential problems of agriculture ecosystems for birds in Japan. Glob Environ Res 5: 151-161.

Galbraith H (1988) Effects of agriculture on the breeding ecology of lapwings Vanellus vanellus. J Anim Ecol 25: 487-504.

Galbraith H, Furness RW \& Fuller RJ (1984) Habitats and distribution of waders breeding on Scottish agricultural land. Scottish Birds 13: 98-107.

Henderson IG, Wilson AM, Steele D \& Vickery JA (2002) Population estimates, trends and habitat associations of breeding lapwing Vanellus vanellus, curlews Numenius arquata and snipe Gallinago gallinago in Northern Ireland in 1999. Bird Study 49: 17-25.
Hoogland JL \& Sherman PW (1976) Advantages and disadvantages of bank swallow (Riparia riparia) coloniality. Ecol Monogr 46: 33-58.

Kis J, Liker A \& Székely T (2000) Nest defence by Lapwings: observations on natural behaviour and an experiment. Ardea 88: 155-163.

Komdeur J (1996) Influence of age on reproductive performance in the Seychelles warbler. Behav Ecol 7: 417-425.

Lack D (1954) The natural regulation of animal numbers. Oxford Univ Press, London.

Lack D (1966) Population studies of birds. Clarendon Press, Oxford.

Lane SJ \& Fujioka M (1998) The impact of changes in irrigation practices on the distribution of foraging egrets and herons (Ardeidae) in the rice fields of central Japan. Biol Conserv 83: 221-230.

Maeda T (1998) Rice fields as an important habitat for birds. Res J Food Agric 21: 27-32.

Maeda T (2001) Patterns of bird abundance and habitat use in rice fields of the Kanto Plain, central Japan. Ecol Res 16: 569-585.

Marini MA, Robinson SK \& Heske EJ (1995) Edge effects on nest predation in the Shawnee National Forest, southern Illinois. Biol Conserv 74: 203-213.

Ministry of Agriculture, Forestry and Fisheries of Japan (MAFF) (1998) Statistics on cropland and planted area in 1997. Association of Agriculture and Forestry statistics, Tokyo.

Ohno Y (1996) Effects of nesting Grey-headed Lapwings Microsarcops cinereus on the intensity of the artificial nest predation by Carrion Crows Corvus corone. Jpn J Ornithol 45: 91-99.

Okugawa KI, Ishii T, Mitsuno M, Hasegawa S, Tsukamoto K, Aoki M, Yamashita S \& Yamamoto S (1970) An ecological study of Macrosarcops cinereus (Blyth), Grey-headed Lapwing (Charadriidae), of the Ogura farm area, Kyoto. Bull Kyoto Univ Edu Ser B 37: 3-87 (in Japanese with English summary).

Pärt T (2001) The effects of territory quality on age-dependent reproductive performance in the northern wheatear Oenanthe oenanthe. Anim Behav 62: 379-388.

Perrins CM \& Middlton ALA (ed) (1984) The encyclopaedia of animals. Equinox Ltd, Oxford.

Šálek M \& Šmilauer P (2002) Predation on Northern Lapwing Vanellus vanellus nests: the effect of population density and spatial distribution of nests. Ardea 90: 51-60.

Sheldon R, Bolton M, Gillings S \& Wilson A (2004) Conservation management of lapwing Vanellus vanellus on lowland arable farmland in the UK. Ibis 146: 41-49. 
Shrubb M (1990) Effects of agricultural change on nesting lapwings Vanellus vanellus in England and Wales. Bird Study 37: 115-127.

Sonobe K \& Robinson JW (1985) A field guide to the birds of Japan. Kodansha international, Tokyo.

Sonobe K \& Usui S (1993) A field guide to the waterbirds of Asia. Wild Bird Society of Japan, Tokyo.

Veen J (1977) Functional and causal aspects of nest distribution in colonies of the sandwich tern (Sternas sandvicensis Lath.). Behav Suppl 20: 1-193.

Walters JR (1990) Anti-predatory behavior of lapwings: field evidence of discriminative abilities. Wilson Bull 102: 49-70.

Wiklund CG \& Andersson M (1994) Natural selection of colony size in a passerine bird. J Anim Ecol 63: 765-774.

Yamazaki M, Hamada Y, Ibuka T, Momii T \& Kimura M (2001) Seasonal variations in the community structure of aquatic organisms in a paddy field under a long-term fertilizer trial. Soil Sci Plant Nutr 47: 587-600.

Yamazaki M, Hamada Y, Kamimoto T, Momii T, Yoshimi I, Yasuda N, Mizuno S, Yoshida S \& Kimura M (2003) Changes in the community structure of aquatic organisms after midseason drainage in the floodwater of Japanese paddy fields. Soil Sci Plant Nutr 49: 125-135. 